\title{
Association of dopaminergic/GABAergic genes with attention deficit hyperactivity disorder in children
}

\author{
GUANG-XIN WANG $^{1}$, YAN-HUI MA ${ }^{1}$, SHI-FU WANG ${ }^{1}$, \\ GUANG-FANG REN ${ }^{2}$ and HUI GUO ${ }^{1}$ \\ ${ }^{1}$ Medical Institute of Paediatrics, Qilu Children's Hospital of Shandong University, Jinan, Shandong 250022; \\ ${ }^{2}$ Department of Outpatients, Linshu People's Hospital of Shandong Province, Linshu, Shandong 276700, P.R. China
}

Received March 16, 2012; Accepted August 1, 2012

DOI: $10.3892 / \mathrm{mmr} .2012 .1028$

\begin{abstract}
Attention deficit hyperactivity disorder (ADHD) is the most commonly diagnosed neurobehavioral disorder in children and adolescents; however, its etiology is unknown. In this study, we investigated the association of five polymorphisms in dopaminergic/GABAergic genes with ADHD using polymerase chain reaction-restriction fragment length polymorphism in a group of 54 children with ADHD and 67 healthy controls. The distribution of AA genotype and A allele frequencies of rs5320 in the dopamine beta-hydroxylase gene in ADHD children differed significantly from that in healthy controls; however, no associations were found between four other polymorphisms in dopaminergic/GABAergic genes and ADHD. We also identified the best model consisting of four loci. We conclude that the rs5320 polymorphism may be considered as a genetic risk factor of ADHD, but the other four polymorphisms were not confirmed to be related directly to ADHD. The multilocus of dopaminergic/GABAergic genes acted in combination to affect susceptibility to ADHD in the children studied.
\end{abstract}

\section{Introduction}

Attention deficit hyperactivity disorder (ADHD) is the most commonly diagnosed neurobehavioral disorder in children and adolescents, and is characterized by several symptoms, particularly inattention, hyperactivity and impulsivity (1). It has been estimated that over $5 \%$ of all school-aged children and adolescents meet criteria for ADHD. ADHD has become a public health problem causing a significant financial cost, stress to families, impact on academic and vocational activities, as well as negative effects on self-esteem (2).

Correspondence to: Professor Yan-Hui Ma, Medical Institute of Paediatrics, Qilu Children's Hospital of Shandong University, 23976 Jingshi Xi Road, Jinan, Shandong 250022, P.R. China E-mail: etyymyh@163.com

Key words: dopaminergic genes, GABAergic genes, attention deficit hyperactivity disorder, association study
Although the etiology of ADHD is unknown, family, twin and adoption studies have demonstrated that ADHD is highly heritable. It is widely accepted that several genes, which include dopamine transporter gene (DAT1), dopamine D4 receptor gene (DRD4), synaptosomal-associated protein of $25 \mathrm{kDa}$ gene (SNAP-25), DRD5, serotonin transporter gene (5-HTT) and serotonin receptor 1B (5-HTR1B), each contributing a small fraction of the total genetic variance, are implicated in ADHD (3). Animal, pharmacological and imaging studies have indicated dopamine system dysfunction in the pathogenesis of ADHD; therefore, dopaminergic system genes may be candidate genes for ADHD (2). Recently, polymorphisms at dopamine-related genes, such as catechol-O-methyltransferase (COMT), DAT1 and DRD4, many of which cause observed alterations in protein function or structure, have been identified, prompting researchers to test their role in increasing the risk of ADHD (4-5). Studies of ADHD have focused less on GABAergic dysfunction than on dopaminergic dysfunction. A study found that the $\gamma$-aminobutyric acid (GABA) level in the blood increased and the ratio of excitatory/inhibitory mediatory amino acids decreased significantly in children with minimal cerebral dysfunction (6); moreover, the GABAergic agent extended-release valproate (EVA) could decrease ADHD symptoms (7-8). Whether GABAergic dysfunction has direct or indirect importance in ADHD is unclear, and an association study between the GABAergic genes and ADHD may be able to clarify its role in the susceptibility to ADHD. To date, the correlation of polymorphisms in GABAergic genes to ADHD has not been reported.

Despite many efforts, the search for susceptibility genes for ADHD has yielded largely inconsistent results. To evaluate the involvement of a series of functional allelic variants of dopaminergic/GABAergic genes in ADHD using polymerase chain reaction-restriction fragment length polymorphism (PCR-RFLP), we genotyped five functional single nucleotide polymorphisms (SNPs), rs6275 polymorphism in the DRD2 gene, rs5320 polymorphism in the dopamine beta-hydroxylase (DBH) gene, rs5326 polymorphism in the DRD1 gene, rs4680 polymorphism in the COMT gene and rs1805057 polymorphism in the gamma-aminobutyric acid $\mathrm{B}$ receptor 1 (GABBR1) gene, in 54 cases of ADHD and 67 healthy controls in Chinese Han children. 
Table I. The sequences of the primers and reaction conditions for dopaminergic/GABAergic genes.

\begin{tabular}{|c|c|c|c|c|}
\hline SNPs & Sequences of primers & $\begin{array}{l}\text { Fragment } \\
\text { size (bp) }\end{array}$ & $\begin{array}{l}\text { Annealing } \\
\left({ }^{\circ} \mathrm{C}\right)\end{array}$ & $\begin{array}{l}\text { Incision } \\
\text { enzyme }\end{array}$ \\
\hline rs4680 & $\begin{array}{l}\text { F (5'-3') GGGGCCTACTGTGGCTACTC } \\
\text { R (5'-3') TTTTCCAGGTCTGACAACGG }\end{array}$ & 173 & 58 & NlaIII \\
\hline rs5326 & $\begin{array}{l}\text { F (5'-3') AAGGGAGTCAGAAGACAGAT } \\
\text { R (5'-3') CAGGCAGTGAGGATACGAAC }\end{array}$ & 317 & 56 & $B f a \mathrm{I}$ \\
\hline rs6275 & $\begin{array}{l}\text { F (5'-3') GGGAGCTGGAGATGGAGATGC } \\
\text { R (5'-3') ATGGGACCTTTCACAGACCG }\end{array}$ & 358 & 59.5 & NcoI \\
\hline rs1805057 & $\begin{array}{l}\text { F (5'-3') AACAGTAACACAAACCATCC } \\
\text { R (5'-3') GCATGTTTGTAGAAGGTGCC }\end{array}$ & 439 & 53 & EagI \\
\hline rs5320 & $\begin{array}{l}\text { F (5'-3') CACTGTCCACTTGGTCTACG } \\
\text { R (5'-3') GCTCCTTAATGTAGCACCAG }\end{array}$ & 218 & 56 & $P m l \mathrm{I}$ \\
\hline
\end{tabular}

SNPs, single nucleotide polymorphisms; F, forward; R, reverse.

\section{Materials and methods}

Sample. In total, 54 ADHD cases (40 males and 14 females) were recruited from the outpatient clinic of Qilu Children's Hospital of Shandong University between January 2009 and June 2010. To be included in the study, children had to meet the following three criteria: i) have a diagnosis of ADHD classified according to the DSM-IV (9); ii) be between the ages of 7 and 16 years and have a full scale IQ above 70 according to the Wechsler Intelligence scale for Chinese children (standardized by Gong Yaoxian); iii) originate from the Han population. Individuals were excluded for any evidence of major neurological conditions or a primary diagnosis of schizophrenia, affective disorder, pervasive developmental disorder or epilepsy. In all patients, $85.7 \%$ had the combined subtype and $14.3 \%$ the inattentive subtype of ADHD.

The healthy control group included 67 healthy children (49 males and 18 females) who underwent a health examination in Qilu Children's Hospital of Shandong University. The group was selected from the Han population and aged from 7 to 16 years. Subjects with relevant psychiatric/psychological or developmental illnesses were excluded. The mean ages of the ADHD and control groups were $9.14(\mathrm{SD}=1.556)$ and $9.06(\mathrm{SD}=1.732)$, respectively. This study was approved by the ethics committee of Qilu Children's Hospital of Shandong University. All subjects were unrelated individuals, and all subjects and their guardians provided written informed consent.

Genotyping. Genomic DNA was extracted from the venous blood of each participant using a TIANamp blood DNA kit (Tiangen Biotech Co. Ltd., Beijing, China). PCR cycling was performed in a DNA thermal cycler with a $2 \mathrm{X}$ Hotstart Taq PCR Mastermix kit (Tiangen Biotech Co. Ltd.). The sequences of the primers and reaction conditions used in this study are shown in Table I.

In a $25 \mu 1$ reaction, $200 \mathrm{ng}$ of genomic DNA was used with $1.0 \mu \mathrm{l}$ of each primer $(10 \mu \mathrm{mol} / \mathrm{l})$ and $12.5 \mu \mathrm{l}$ of $2 \mathrm{X}$ Hotstart Taq
PCR Mastermix. Samples were amplified using the following cycles: initial denaturation of $3 \mathrm{~min}$ at $94^{\circ} \mathrm{C}$, then $35 \mathrm{sec}$ of denaturation at $94^{\circ} \mathrm{C}, 35 \mathrm{sec}$ at the annealing temperature, and $50 \mathrm{sec}$ of extension at $72^{\circ} \mathrm{C}$, repeated for 31 cycles and followed by another $5 \mathrm{~min}$ period of extension at $72^{\circ} \mathrm{C}$. PCR products were further purified, and then digested by NlaIII, $B f a \mathrm{I}, N c o \mathrm{I}, E a g \mathrm{I}$ and PmlI, respectively. The digested PCR products were confirmed by electrophoresis on $2.5 \%$ agarose gels. Genotypes were determined by gel image processing software.

Statistical analysis. The data were statistically processed with SPSS 11.0 software (SPSS, USA). Allele and genotype frequencies were compared between two groups using the Chi-square test. Observed and expected allele frequencies within populations were compared by means of a Hardy-Weinberg test. To determine high- and low-risk genotype combinations, a multifactor dimensionality reduction (MDR) method was used. This procedure was specifically developed to detect higher order interactions between polymorphisms to predict a dichotomous trait variation, even when the marginal effects were very small. The fitness of an MDR model was assessed by estimating the testing accuracy; models that were true positive would have an estimated testing accuracy of 0.5 .

\section{Results}

Detection of genotypes of dopaminergic/GABAergic genes. The $\mathrm{A}_{260} / \mathrm{A}_{280}$ ratios of genomic DNA from blood specimens were 1.7-1.9; this meant that the genomic DNA was eligible to be used as a template for PCR. By PCR, a 173 bp fragment was amplified from the COMT gene, a $439 \mathrm{bp}$ fragment from the GABBR1 gene, a 218 bp fragment from the DBH gene, a 317 bp fragment from the DRD1 gene, and a 358 bp fragment from the DRD2 gene, as shown in Fig. 1.

At the rs4680 polymorphism in the COMT gene digested by NlaIII, there were three genotypes: a) the predominant 


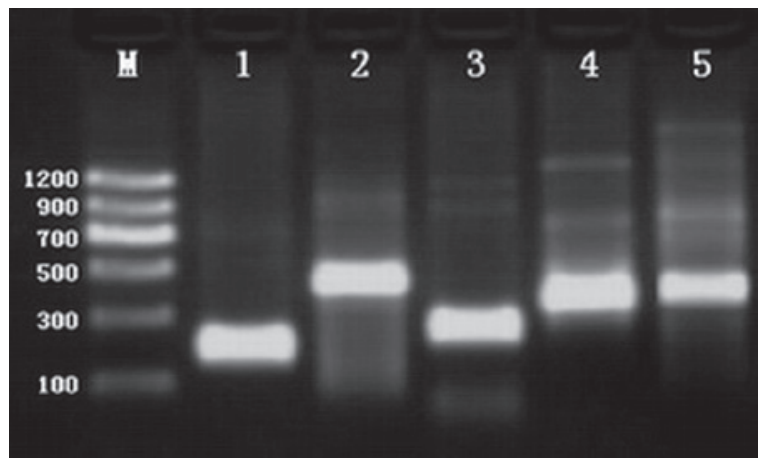

Figure 1. Electrophoresis of dopaminergic/GABAergic genes. PCR products: M, DNA marker; Lane 1, PCR product of the COMT gene was $173 \mathrm{bp}$; Lane 2, PCR product of the GABBR1 gene was $439 \mathrm{bp}$; Lane 3, PCR product of the DBH gene was $218 \mathrm{bp}$; Lane 4, PCR product of the DRD1 gene was $317 \mathrm{bp}$; Lane 5, PCR product of the DRD2 gene was $358 \mathrm{bp}$.

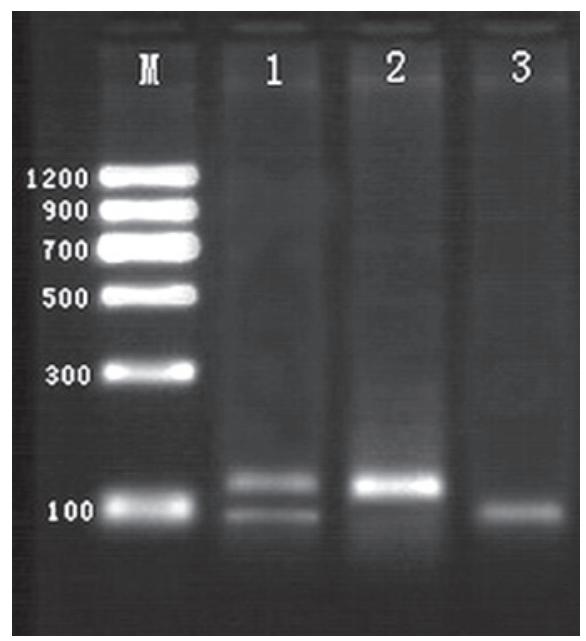

Figure 2. Restriction endonuclease analysis of polymorphism rs4680 in the COMT gene. M, DNA marker; Lane 1, GA 18, 26, 33, 96 and 114 bp. Lane 2, GG genotype 26, 33 and 114 bp. Lane 3, AA 18, 26, 33 and 96 bp (18, 26 and 33 bp cannot be seen).

homozygote, GG, indicated by three fragments $(26,33$ and $114 \mathrm{bp})$; b) the heterozygote, GA, indicated by five fragments $(18,26,33,96$ and $114 \mathrm{bp})$; and c) the rare homozygote, AA, as shown in Fig. 2 (18, 26 and 33 bp cannot be seen). At the rs5326 polymorphism in the DRD1 gene digested by $B f a \mathrm{I}$, there were three genotypes: a) the predominant homozygote, $\mathrm{GG}$, indicated by one fragment (317 bp); b) the heterozygote, GA, indicated by three fragments $(139,178$ and $317 \mathrm{bp}$; and c) the rare homozygote, AA, as shown in Fig. 3. At the rs6275 polymorphism in the DRD2 gene digested by NcoI, there were three genotypes: a) the $\mathrm{CC}$ genotype, indicated by one fragment (358 bp); (b) the heterozygote, CT, indicated by three fragments (106, 252 and $358 \mathrm{bp}$ ); and c) the TT genotype, as shown in Fig. 4. At the rs 1805057 polymorphism in the GABBR1 gene digested by EagI, only the GG genotype was observed in all patients and controls, as shown in Fig. 5. At the rs5320 polymorphism in the DBH gene digested by PmlI, there were three genotypes: a) the predominant homozygote, $\mathrm{GG}$, indicated by one fragment (218 bp); b) the heterozygote,

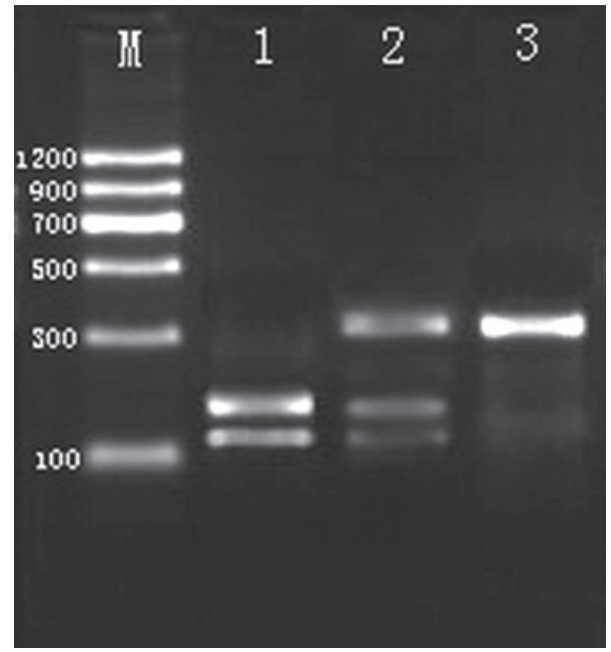

Figure 3. Restriction endonuclease analysis of polymorphism rs5326 in the DRD1 gene. M, DNA marker; Lane 1, AA genotype 139 and 178 bp; Lane 2, GA genotype 317, 139 and 178 bp; Lane 3, GG genotype 317 bp.

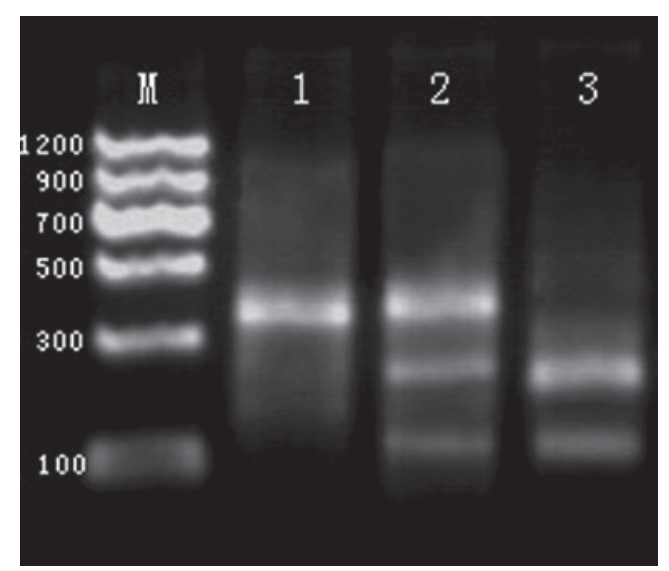

Figure 4. Restriction endonuclease analysis of polymorphism rs6275 in the DRD2 gene. M, DNA marker; Lane 1, CC genotype 358 bp; Lane 2, CT genotype 106, 252 and 358 bp; Lane 3, TT genotype 106 and 252 bp.

GA, indicated by three fragments (77, 141 and $218 \mathrm{bp}$; and c) the rare homozygote, AA, as shown in Fig. 6.

Hardy-Weinberg equilibrium. No significant differences were found between the ADHD and control groups in the genotypic frequencies of the rs6275 polymorphism $\left(\chi^{2}=0.601,0.071\right.$, $\mathrm{P}>0.05)$, rs5320 polymorphism $\left(\chi^{2}=0.888,0.023, \mathrm{P}>0.05\right)$, rs5326 polymorphism $\left(\chi^{2}=0.184,0.207, \mathrm{P}>0.05\right)$ and $\mathrm{rs} 4680$ polymorphism $\left(\chi^{2}=0.264,0.071, P>0.05\right)$, and the results showed goodness of fit for Hardy-Weinberg equilibrium, indicating that population stratification was not a factor in the results.

Genotypes and allele frequencies of four polymorphisms in dopaminergic/GABAergic genes in two groups. The distribution of the AA genotype and A allele frequencies of the rs5320 polymorphism in the DBH gene in ADHD children differed significantly from that in healthy controls $(\mathrm{P}=0.016,0.014$; $\mathrm{OR}=9.484,2.222$, respectively). The genotype distribution 
Table II. Comparisons of genotypes and allele frequencies of four polymorphisms in dopaminergic/GABAergic genes in two groups.

\begin{tabular}{|c|c|c|c|c|c|c|}
\hline \multirow{2}{*}{$\begin{array}{l}\text { Groups } \\
\text { rs5320 }\end{array}$} & \multirow[t]{2}{*}{$\mathrm{n}$} & \multicolumn{3}{|c|}{ Genotypes [n (\%)] } & \multicolumn{2}{|c|}{ Allele frequencies $(\%)$} \\
\hline & & AA & $\mathrm{AG}$ & GG & A & $\mathrm{G}$ \\
\hline ADHD group & 54 & $6(11.1)^{\mathrm{a}}$ & $17(31.5)$ & $31(57.4)$ & $26.9^{\mathrm{b}}$ & 73.1 \\
\hline Control group & 67 & $1(1.5)$ & $17(25.4)$ & $49(73.1)$ & 14.2 & 85.8 \\
\hline rs6275 & & $\mathrm{TT}$ & $\mathrm{TC}$ & $\mathrm{CC}$ & $\mathrm{T}$ & $\mathrm{C}$ \\
\hline ADHD group & 54 & $10(18.5)^{\mathrm{c}}$ & $31(57.4)$ & $13(24.1)$ & $47.2^{c}$ & 52.8 \\
\hline Control group & 67 & $21(31.3)$ & $34(50.8)$ & $12(17.9)$ & 56.7 & 43.3 \\
\hline rs5326 & & GG & GA & AA & $\mathrm{G}$ & A \\
\hline ADHD group & 54 & $25(46.3)^{\mathrm{d}}$ & $22(40.7)$ & $7(13.0)$ & $66.7^{\mathrm{d}}$ & 33.3 \\
\hline Control group & 67 & $39(58.2)$ & $23(34.3)$ & $5(7.5)$ & 75.4 & 24.6 \\
\hline rs4860 & & AA & $\mathrm{AG}$ & GG & A & $\mathrm{G}$ \\
\hline ADHD group & 54 & $4(7.4)^{\mathrm{e}}$ & $18(33.3)$ & $32(59.3)$ & $24.1^{\mathrm{e}}$ & 75.9 \\
\hline Control group & 67 & $3(4.5)$ & $22(32.8)$ & $42(62.7)$ & 20.9 & 79.1 \\
\hline
\end{tabular}

${ }^{\mathrm{a}}$ vs. control group, $\chi^{2}=5.809, \mathrm{P}=0.016$; OR: 9.484 , 95\% CI: 1.089-82.587. ${ }^{\mathrm{b}} \mathrm{vs}$. control group, $\chi^{2}=6.040, \mathrm{P}=0.014 ; \mathrm{OR}: 2.222,95 \% \mathrm{CI}$ : 1.165-4.237. ${ }^{\mathrm{c}} \mathrm{vs}$. control group, $\chi^{2}=2.716,2.003 ; \mathrm{P}>0.05$. ${ }^{\mathrm{d}} \mathrm{vs}$. control group, $\chi^{2}=2.045,1.554 ; \mathrm{P}>0.05$. ${ }^{\mathrm{e}} \mathrm{vs}$. control group, $\chi^{2}=0.503,0.258$; $\mathrm{P}>0.05$. ADHD, attention deficit hyperactivity disorder.

Table III. Gene-gene interaction model and characteristics.

\begin{tabular}{lcc}
\hline Model & $\begin{array}{c}\text { rs5320/rs6275/ } \\
\text { rs5326 }\end{array}$ & $\begin{array}{c}\text { rs5320/rs6275/ } \\
\text { rs5326/rs4680 }\end{array}$ \\
\hline Training accuracy & 0.6731 & 0.741 \\
Test accuracy & 0.4959 & 0.6198 \\
$\chi^{2}$ & 12.2003 & 24.3338 \\
Significance test (P) & 0.0005 & $<0.0001$ \\
CV consistency & $9 / 10$ & $10 / 10$ \\
Sensitivity & 0.5988 & 0.6461 \\
Specificity & 0.733 & 0.8176 \\
Odds ratio & 4.0969 & 8.1819 \\
95\% CI & $1.8243-9.2006$ & $3.3967-19.7084$ \\
\hline
\end{tabular}

CV, cross-validation.

and allele frequencies of the rs 6275 polymorphism in the DRD2 gene, the rs5326 polymorphism in the DRD1 gene and the rs4680 polymorphism in the COMT gene showed no significant difference between ADHD children and healthy controls $\left(\chi^{2}=2.716,2.003 ; \chi^{2}=2.045,1.554 ; \chi^{2}=0.503,0.258\right.$, respectively, $\mathrm{P}>0.05)$, as shown in Table II.

MDR analysis. Multilocus analysis was performed using the MDR method. Of all the models analyzed, one four-locus model had a maximum cross-validation consistency of ten out of ten, a maximum prediction accuracy of $61.98 \%$, and a maximum sensitivity of $64.61 \%$. It also had the smallest $\mathrm{P}$-value in the sign test for cross-validation $(\mathrm{P}<0.0001)$. The best model contains four-locus SNPs consisting of rs5320, rs6275, rs5326 and rs4680, as shown in Table III.

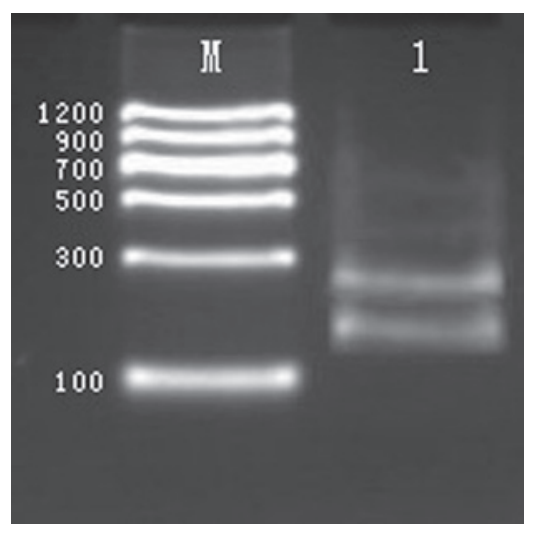

Figure 5. Restriction endonuclease analysis of polymorphism rs1805057 in the GABBR1 gene. M, DNA marker; Lane 1, genotype 182 and 257 bp.

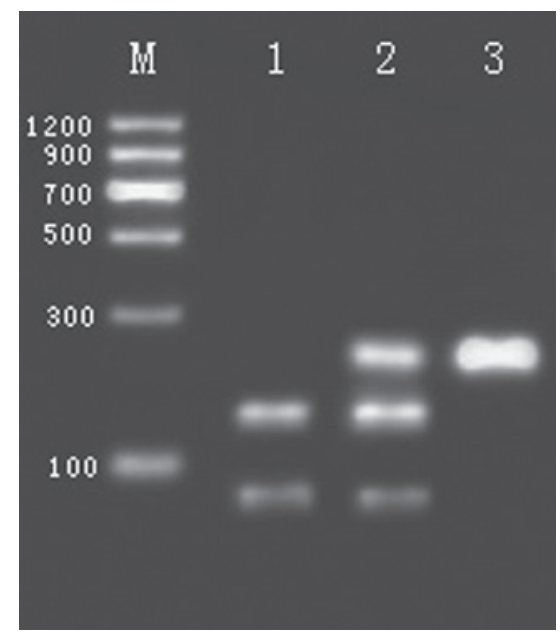

Figure 6. Restriction endonuclease analysis of polymorphism rs5320 in the DBH gene. M, DNA marker; Lane 1, AA genotype 77 and 141 bp; Lane 2, GA genotype 77, 141 and 218 bp; Lane 3, GG genotype 218 bp. 


\section{Discussion}

ADHD is associated with impaired school performance, peer relationships, parent-child relationships, behavior and emotions (10-11). The incidence has been increasing year by year. Although the etiology of ADHD is not fully understood, convincing data support the hypothesis that genetic factors play a fundamental role in the etiology of ADHD. The estimated heritability of ADHD is 70-90\% (12).

Several lines of evidence indicate dopamine system dysfunction in the pathogenesis of ADHD (13). It is widely accepted that dopaminergic genes, encoding for enzymes, receptors and transporters, each contributing a small fraction of the total genetic variance, are implicated in ADHD $(5,14)$.

$\mathrm{DBH}$ is responsible for conversion of dopamine to norepinephrine. It is released along with catecholamines from the adrenal medulla and from sympathetic nerve endings, and its coding gene has been mapped to chromosome 9q34 (15). Numerous polymorphisms in the DBH gene have been found to independently exert their direct effect on the enzyme activity. Kopecková et al found that the risk of ADHD was significantly increased in the presence of the A allele of polymorphism G444A as well as in the presence of the $\mathrm{T}$ allele of polymorphism C1603T in the DBH gene (16). Another study found that the $-1021 \mathrm{C} / \mathrm{T}$ polymorphism, accounting for up to $50 \%$ of the enzymatic activity, was associated with ADHD (17). Further study is required to determine whether other polymorphisms are involved in the development of ADHD. In this study, a functional polymorphism, rs5320 in the DBH gene, was observed with PCR-RFLP analysis in 54 cases of ADHD and 67 healthy controls, and the distribution of the AA genotype and A allele frequencies of this polymorphism in ADHD children differed significantly from that in healthy controls. Our finding introduces a novel exonic SNP in the DBH gene showing a putative association with ADHD, which adds further support for the involvement of the $\mathrm{DBH}$ gene in ADHD. However, the sample size in this study is relatively small, which decreased statistical power, so the results may be due to chance although nominally significant. Moreover, this finding requires replication in independent populations of various ethnic origins.

Evidence from human and animal studies suggested that the DRD1 gene was a good candidate for involvement in ADHD (18). Bobb et al found that ADHD probands were more likely than controls to have the $\mathrm{C}$ allele of rs4532 and the A allele of rs265981 in the DRD1 gene (19). Another polymorphism -94 G/A (rs5326) in the DRD1 gene was evaluated in this study, and the genotype distribution and allele frequencies of this polymorphism showed no significant difference between children with ADHD and healthy controls. There are several possible explanations for this negative result. First, this selected SNP has a very small main effect or no direct effect on ADHD, or our sample lacked the power to detect it. Second, it is feasible that environmental risk factors may interact with genetic risk factors, reducing or abolishing its main effect from genotype alone; in this case we would have little chance of detecting such associations unless we had also measured environmental risk factors.

DRD2-deficient mice displayed reduced locomotor activity, as well as reduced spontaneous movements (20).
The human DRD2 gene is located on chromosome 11q22-23, and consists of 8 exons separated by 7 introns (21). Several polymorphisms were identified shortly after the gene was cloned; these SNPs include the TaqI restriction site (TaqI sites 'A', 'B' and 'D') and one short tandem repeat polymorphism. Some research found a highly positive correlation between ADHD and TaqI A polymorphism (rs1800497) in the DRD2 gene (22-23). However, results of a study by Todd et al did not support the DRD2 gene TaqI A contributing to susceptibility for ADHD (24). This study explored a functional polymorphism, rs6275 in the DRD2 gene, to expound the involvement of the gene in ADHD, but we failed to establish whether the genotype distribution and allele frequencies of this polymorphism were significantly different between children with ADHD and healthy controls. The inconsistency of the previous association studies between the DRD2 gene and ADHD may be due to genetic heterogeneity, which is a significant challenge in the genetic study of ADHD. It could also be argued that ethnic differences, sample demographics, such as gender stratification due to the predominance of male subjects, and study populations with comorbidity in these studies accounted for the contradictory results. Further studies including larger sample sizes are certainly required to confirm whether the rs6275 polymorphism in the DRD2 gene is associated with ADHD. Moreover, the association between other DRD2 gene polymorphisms and ADHD requires further investigations to determine the role of the DRD2 gene in ADHD.

COMT plays a crucial role in the metabolism of catecholamines in the frontal cortex, and its encoding gene is on chromosome 22q11.2. Interest in COMT comes from its involvement in dopaminergic pathways. The most studied polymorphism in COMT is an SNP, Val158Met (rs4680), which leads to either methionine (Met) or valine (Val) at codon 158, resulting in a three- to four-fold reduction in COMT activity. This polymorphism is functional with the val/ val genotype increasing enzyme activity. Pálmason et al found that the Met allele of Val158Met was associated with ADHD and increased ADHD symptom severity (25). Contrary to the previously observed association, we failed to gain a positive result for rs4680 in COMT. The possible explanations for this include the heterogeneity between our sample and others, and the possibility that these results are false-negative findings.

GABA is the principal inhibitory neurotransmitter in the human brain. Since ADHD is a disorder of disinhibition, it is reasonable to suggest that genetic defects in GABA could be involved (26). GABA exerts its effects mainly through two receptor subtypes termed A and B. GABA B receptors, including subunit 1 and 2 , are highly expressed in the limbic system. In 1998, the gene encoding GABA B receptors subunit 1 (GABBR1) was cloned, and several polymorphisms of the human GABBR1 gene were identified, but only two were missense mutations. The missense mutation G1465A (rs1805057) led to an amino acid substitution, Gly489Ser, within the N-terminal extracellular domain of GABBR1, which was necessary for heteromeric assembly of such a receptor and, therefore, may affect its ligand binding properties. To explore the possible role of the rs 1805057 polymorphism in the etiology of ADHD, we examined the distribution of genotypes and allele frequencies of this SNP; however, only genotype GG was observed in all patients and healthy controls. This study 
failed to document any association between the rs 1805057 polymorphism and ADHD, and this polymorphism may be ethno-geographically localized.

In general, the dopamine receptors are found on inhibitory GABA neurons (27). Certain studies showed that dopaminergic receptors, such as the D2 receptor were involved in regulating GABA synthesis in the striatonigral system. On the other hand, the GABA B subtype of receptor, not the GABA A subtype, is possibly involved in reducing the release of dopamine and controlling the activity of nigrostriatal dopaminergic neurons by regulating the cAMP-generating system (28-29). Interactions of the dopaminergic and GABAergic system may play a role in the pathogenesis of ADHD. In addition, ADHD is a multigene disease, and the SNP association study in one gene was insufficient to explain the complex genetic basis of ADHD susceptibility. Therefore, in this study, we evaluated the multilocus genetic interactions involved in the development of ADHD using MDR analysis. Of the models detected using MDR, we chose the four-locus model as the best one for determining ADHD susceptibility based on its balanced accuracy and cross-validation consistency. This model included four genotypes: rs5320 polymorphism, rs6275 polymorphism, rs5326 polymorphism and rs4680 polymorphism in dopaminergic genes, which may contribute more markedly to susceptibility to ADHD than any single genetic polymorphism.

In conclusion, our findings suggested that rs 5320 polymorphism in the DBH gene was likely to be associated with the susceptibility to ADHD in Chinese Han children, but rs6275 polymorphism in the DRD2 gene, rs5326 polymorphism in the DRD1 gene, rs4680 polymorphism in the COMT gene, and rs1805057 polymorphism in the GABBR1 gene, were not confirmed to be directly related to ADHD. A multilocus SNP, including rs5320, rs6275, rs5326 and rs4680 polymorphisms in dopaminergic/GABAergic genes, acted in combination to affect the susceptibility to ADHD, and the potential gene-gene interaction existed among dopaminergic/GABAergic genes in the genetic pathology of ADHD.

\section{Acknowledgements}

The authors gratefully extend their gratitude to all subjects for their participation and cooperation in this study, as well as to Da-wei Wang for rewriting the manuscript.

\section{References}

1. Hong Q, Wang YP, Zhang M, et al: Homer expression in the hippocampus of an animal model of attention-deficit/hyperactivity disorder. Mol Med Report 4: 705-712, 2011.

2. Genro JP, Kieling C, Rohde LA and Hutz MH: Attention-deficit/ hyperactivity disorder and the dopaminergic hypotheses. Expert Rev Neurother 10: 587-601, 2010.

3. Elia J and Devoto M: ADHD genetics: 2007 update. Curr Psychiatry Rep 9: 434-439, 2007.

4. Sharp SI, Mcquillin A and Gurling HM: Genetics of attentiondeficit hyperactive disorder (ADHD). Neuropharmacology 57: 590-600, 2009.

5. Gizer IR, Ficks C and Waldman ID: Candidate gene studies of ADHD: a meta-analytic review. Hum Genet 126: 51-90, 2009.

6. Kolesnichenko LS, Kulinskiı̌ VI and Gorina AS: Amino acids and their metabolites in blood and urine of children with minimal cerebral dysfunction. Vopr Med Khim 45: 58-64, 1999 (In Russian).
7. Miyazaki M, Ito H, Saijo T, et al: Favorable response of ADHD with giant SEP to extended-release valproate. Brain Dev 28: 470-472, 2006.

8. Powell SG, Thomsen PH, Frydenberg M and Rasmussen H: Long-term treatment of ADHD with stimulants: a large observational study of real-life patients. J Atten Disord 15: 439-451, 2011.

9. American Psychiatric Association (APA): Diagnostic and statistical manual of mental disorders. 4th ed. American Psychiatric Press, Washington DC, 1994.

10. Li J, Kang C, Zhang H, et al: Monoamine oxidase A gene polymorphism predicts adolescent outcome of attention-deficit/ hyperactivity disorder. Am J Med Genet B 144B: 430-433, 2007.

11. Barnard-Brak L, Sulak TN and Fearon DD: Coexisting disorders and academic achievement among children with ADHD. J Atten Disord 15: 506-515, 2011.

12. Domschke K, Sheehan K, Lowe N, et al: Association analysis of the monoamine oxidase A and $\mathrm{B}$ genes with attention deficit hyperactivity disorder (ADHD) in an Irish sample: preferential transmission of the MAO-A $941 \mathrm{G}$ allele to affected children. Am J Med Genet B Neuropsychiatr Genet 134B: 110-114, 2005.

13. DiMaio S, Grizenko N and Joober R: Dopamine genes and attention-deficit hyperactivity disorder: a review. J Psychiatry Neurosci 28: 27-38, 2003.

14. Fisher SE, Francks C, McCracken JT, et al: A genomewide scan for loci involved in attention-deficit/hyperactivity disorder. Am J Hum Genet 70: 1183-1196, 2002.

15. Craig SP, Buckle VJ, Lamouroux A, Mallet J and Craig IW: Localization of the human dopamine beta hydroxylase (DBH) gene to chromosome 9q34. Cytogenet Cell Genet 48: 48-50, 1988 .

16. Kopecková M, Paclt I, Petrásek J, Pacltová D, Malíková M and Zagatová V: Some ADHD polymorphisms (in genes DAT1, DRD2, DRD3, DBH, 5-HTT) in case-control study of 100 subjects 6-10 age. Neuro Endocrinol Lett 29: 246-251, 2008.

17. Kieling C, Genro JP, Hutz MH and Rohde LA: The $-1021 \mathrm{C} / \mathrm{T}$ DBH polymorphism is associated with neuropsychological performance among children and adolescents with ADHD. Am J Med Genet B Neuropsychiatr Genet 147B: 485-490, 2008.

18. Misener VL, Luca P, Azeke O, et al: Linkage of the dopamine receptor D1 gene to attention-deficit/hyperactivity disorder. Mol Psychiatry 9: 500-509, 2004.

19. Bobb AJ, Addington AM, Sidransky E, et al: Support for association between ADHD and two candidate genes: NET1 and DRD1. Am J Med Genet B Neuropsychiatr Genet 134B: 67-72, 2005.

20. Balk JH, Picetti R, Saiardi A, et al: Parkinsonian-like locomotor impairment in mice lacking dopamine D2 receptors. Nature 377: 424-428, 1995.

21. Grandy DK, Litt M, Allen L, et al: The human dopamine D2 receptor gene is located on chromosome 11 at q22- q23 and identifies a TaqI RFLP. Am J Hum Genet 45: 778-785, 1989.

22. Paclt I, Drtilkova I, Kopeckova M, Theiner P, Serý O and Cermakova N: The association between TaqI A polymorphism of ANKK1 (DRD2) gene and ADHD in the Czech boys aged between 6 and 13 years. Neuro Endocrinol Lett 31: 131-136, 2010.

23. Serý O, Drtílková I, Theiner P, et al: Polymorphism of DRD2 gene and ADHD. Neuro Endocrinol Lett 27: 236-240, 2006.

24. Todd RD and Lobos EA: Mutation screening of the dopamine D2 receptor gene in attention-deficit hyperactivity disorder subtypes: preliminary report of a research strategy. Am J Med Genet 114: 34-41, 2002.

25. Pálmason H, Moser D, Sigmund J, et al: Attention-deficit/ hyperactivity disorder phenotype is influenced by a functional catechol-O-methyltransferase variant. J Neural Transm 117: 259-267, 2010.

26. Comings DE: Clinical and molecular genetics of ADHD and Tourette syndrome. Two related polygenic disorders. Ann N Y Acad Sci 931: 50-83, 2001.

27. Sagvolden T, Johansen EB, Aase $H$ and Russell VA: A dynamic developmental theory of attention-deficit/ hyperactivity disorder (ADHD) predominantly hyperactive/impulsive and combined subtypes. Behav Brain Sci 28: 397-468, 2005.

28. Amantea D and Bowery NG: Reduced inhibitory action of a GABAB receptor agonist on $[3 \mathrm{H}]$-dopamine release from rat ventral tegmental area in vitro after chronic nicotine administration. BMC Pharmacol 4: 24, 2004.

29. Hossain MA and Weiner N: Interactions of dopaminergic and GABAergic neurotransmission: impact of 6-hydroxydopamine lesions into the substantia nigra of rats. J Pharmacol Exp Ther 275: 237-244, 1995. 